IN-20

136217

NASA Contractor Report 190795

P.14

\title{
Numerical Study of Cathode Emission Constraints on Cylindrical Self-Field MPD Thruster Performance
}

Michael R. LaPointe

Sverdrup Technology, Inc.

Lewis Research Center Group

Brook Park, Ohio

January 1993

Prepared for

Lewis Research Center

Under Contract NAS3-25266

N/SA

National Aeronautics and Space Administration
(NASA-CR-190795) NUMERICAL STUDY

OF CATHOOE EMISSION CONSTRAINTS ON

CYLINDRICAL SELF-FIELD MPC THRUSTER PERFORMANCE Final Report (Sverurup Technology) $14 \mathrm{p}$
N93-15370

Unclas 


\title{
NUMERICAL STUDY OF CATHODE EMISSION CONSTRAINTS ON CYLINDRICAL, SELF-FIELD MPD THRUSTER PERFORMANCE
}

\author{
Michael R. LaPointe \\ Sverdrup Technology, Inc. \\ 2001 Aerospace Parkway \\ Brook Park, OH 44142
}

(216) $977-7453$

\begin{abstract}
$\underline{\text { Abstract }}$
A stability equation relating thruster discharge current, argon propellant mass flow rate, and electrode geometry has been solved for a variety of cylindrical self-field MPD thruster configurations and discharge currents. Realistic values for cathode emission current densities were used to provide additional constraints on the thruster geometries. A two-dimensional MPD code was employed to provide better estimates of the maximum achievable specific impulse, thrust, and flow efficiency for cases of interest. The model results indicate that long life, cylindrical self-field MPD thrusters operated with argon propellant may not be able to provide specific impulse values in excess of $2100 \mathrm{~s}$. Alternate electrode geometries, applied magnetic fields, and/or low molecular weight propellants may be necessary to achieve higher values of specific impulse.
\end{abstract}

\section{INTRODUCTION}

Nuclear electric propulsion (NEP) has been identified as an attractive option for the low power robotic missions and high power cargo and piloted missions envisioned by the national Space Exploration Initiative (Stone 1992). The magnetoplasmadynamic (MPD) thruster is a robust electric propulsion device with the potential to satisfy these mission requirements. In its basic form, the MPD thruster consists of a cylindrical cathode surrounded by a concentric anode (Figire 1). An arc struck between the electrodes ionizes a gaseous propellant, and the interaction of the arc current with the self-induced magnetic field accelerates the plasma to produce thrust. Steady-state MPD thrusters have been operated at power levels approaching $600 \mathrm{~kW}_{c}$, while pulsed, quasi-steady devices have been operated in the megawatt power range (Sovey and Mantenieks 1988 and Myers et al. 1991). The engine is designed to provide low, continuous thrust with specific impulse $\left(\mathrm{I}_{s_{\mathrm{T}}}\right)$ values of 1000 to $5000 \mathrm{~s}$. The ability to scale MPD thrusters in size and power permits an evolutionary approach toward NEP utilization, concurrent with the evolution of space nuclear power systems.

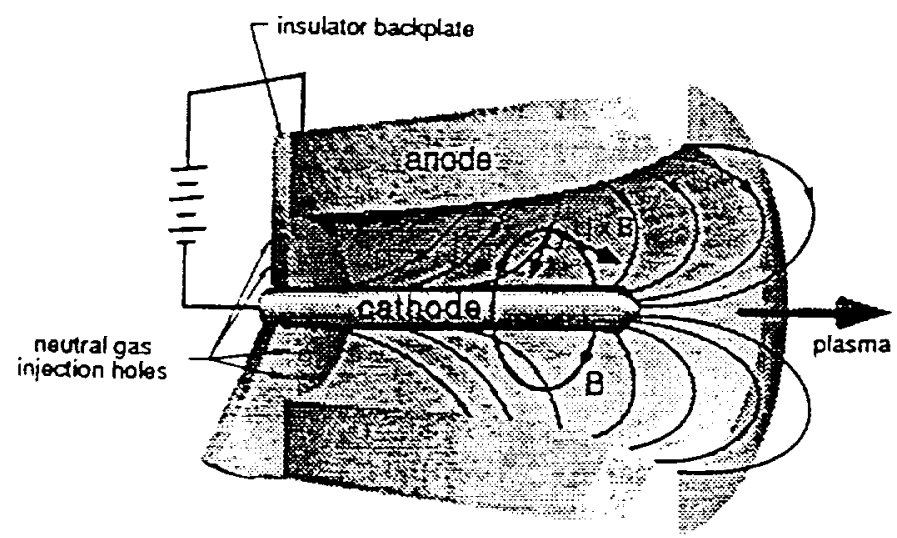

FIGURE 1. Schematic of Self-Field Magnetoplasmadynamic (MPD) Thruster (from Choueiri 1991). 
Although simple in design and robust in operation, MPD thruster performance is limited by low thrust efficiency in the operating regimes of interest (Sovey and Mantenieks 1988 and Myers et al. 1991). Applied magnetic fields (Myers et al. 1991) and flared electrodes (Tahara et al. 1987) have been shown to impact MPD thruster efficiency and specific impulse, but for reasons poorly understood at present. Discharge current is sustained by thermionic emission from the cathode, and if not properly sized the evaporation of cathode material leads to limited thruster life (Myers et al. 1991). In addition, severe electrode erosion has been observed at higher values of specific impulse, corresponding to the onset of voltage oscillations and unsteady thruster operation. Several mechanisms have been proposed to explain the onset of these instabilities, including anode mass starvation (Hugel 1980), flow choking due to enhanced back-emf (Lawless and Subramaniam 1987 and Subramaniam and Lawless 1988), and the triggering of electrothermal and gradient driven instabilities as the plasma approaches full ionization (Preble 1990, Niewood et al. 1990, and Wagner et al. 1990). Different operating conditions may trigger one or a combination of the proposed mechanisms, limiting thruster performance and lifetime. On a less dramatic scale, the occurrence of plasma microturbulence has been predicted (Choueiri 1991) and experimentally observed (Choueiri 1991 and Tilley 1991 ) in MPD thrusters over a range of operating conditions. The presence of microturbulence may enhance the plasma resistivity, resulting in anomalous energy dissipation and a reduction in thruster efficiency.

\section{Numerical Simulation}

A 2-D code has been developed at the National Aeronautics and Space Administration (NASA) Lewis Research Center to predict steady-state, self-field MPD thruster performance (LaPointe 1991 and 1992). The numerical simulation is based upon a fully-ionized, single fluid approximation to the MHD equations, including viscous forces, classical plasma transport coefficients, and Hall effects. Maxwell's equations and a generalized form of Ohm's law (which neglects electron pressure gradients) are used to couple the electromagnetic equations to the fluid equations. A single temperature version of the model was used to predict the thrust, plasma voltage, and flow efficiency of cylindrical and flared MPD thruster geometries assuming a fully ionized argon propellant (LaPointe 1991). Thrust predictions agreed with experimentally determined values, and voltage-current predictions followed experimentally observed trends. The model does not simulate electrode falls or microturbulent plasma processes, and the calculated plasma voltage drops were significantly lower than the experimentally measured total discharge voltages.

A more recent version of the code employing separate ion and electron energy equations (LaPointe 1992) has been used to predict the performance of a matrix of cylindrical self-ficld thruster geometries over a range of operating conditions, again assuming a fully ionized argon propellant. Results of the two-temperature simulations indicate that self-field thruster operation at high specific impulse requires short electrode lengths for stable operation, while longer electrodes are required at low specific impulse to improve thruster flow efficiency. The specific impulse for a self-field MPD thruster is related to $J^{2} / \dot{m}$, a parameter which is often used to characterize MPD thruster performance (Myers et al. 1991). High values of $J^{2} / \dot{m}$ correspond to predominantly electromagnetic acceleration and higher values of specific impulse, while low values of $J^{2} / \dot{m}$ correspond to predominantly electrothermal acceleration, and lower values of specific impulse. For reasons not well understood at present, the numerical simulations did not converge for certain combinations of geometry and $J^{2} / \dot{m}$. Using numerical convergence as a criterion, an equation was formulated which related the maximum stable value of $J^{2} / \dot{m}$ to the simulated cylindrical thruster geometries:

$$
\left(\frac{J^{2}}{\dot{m}}\right)_{c} \leq \frac{6.25 \times 10^{10}}{R_{c}}\left(\frac{L_{c}}{L_{a}}\right)\left[5-\left(\frac{L_{a}}{R_{n}}\right)+4\left(\frac{\left.10 R_{c}-R_{a}\right)}{25}\right)\right] \quad A^{2}-s / k g
$$

where $J$ is the discharge current (amps), $\dot{m}$ is the argon propellant mass flow rate $(\mathrm{kg} / \mathrm{s})$, and $R_{a}, L_{a}, R_{c}$ and $L_{c}$ are the anode radius and length and cathode radius and length, respectively, measured in millimeters. The validity of Equation 2 is limited to straight cylindrical electrodes, uniform argon propellant injection at the backplate, $R_{c} \geq 5 \mathrm{~mm}, R_{n} \geq 25 \mathrm{~mm}, 5 \leq R_{a} / R_{c} \leq 10, L_{n} / R_{n} \leq 5$, and approximately equal electrode lengths $\left(L_{n} \simeq L_{c}\right)$. The onset of thruster instability with increasing $J^{2} / \dot{m}$ has been observed experimentally, and a comprehensive data base listing maximum $J^{2} / \dot{m}$ values for a variety of cylindrical thruster geometries was compiled by Preble (1990). The maximum stable $J^{2} / \dot{m}$ values predicted by Equation 1 were compared to the experimentally determined values of $J^{2} / \dot{m}$ at onset for thruster geometries which 
satisfied the constraints associated with Equation 1 (LaPointe 1992). The predicted onset values were within $20 \%$ of the experimentally determined values, indicating that Equation 1 could be used to estimate maximum stable $J^{2} / \dot{m}$ values for cylindrical, self-field thruster geometries subject to the constraints outlined above.

A constraint not previously considered in MPD thruster modeling is the minimum cathode surface area required to support the thruster discharge current via thermionic emission. To sustain cathode integrity over the thousands of hours required for typical low thrust mission profiles, the cathode temperature should be limited to values below approximately $1470 \mathrm{~K}$ (Schroff et al. 1981 and Gilland et al. 1990). The corresponding current densities for impregnated tungsten rod cathodes lies between $10-20 \mathrm{~A} / \mathrm{cm}^{2}$, the latter value used by Myers et al. (1992) in designing a rod cathode for megawatt MPD thruster applications. For a given discharge current, and assuming uniform thermionic emission from the surface, the minimum required cathode surface area is simply the discharge current divided by the emission current density. For a given cathode radius, the minimum surface area requirement determines a minimum cathode length for use in the numerical simulations. The constraints on cathode surface area, combined with the geometric constraints associated with Equation 1, provide a method to determine the maximum $J^{2} / \dot{m}$ value consistent with long-life, cylindrical self-field thruster operation.

The maximum $J^{2} / \dot{m}$ values predicted by Equation 1 are associated with thruster regimes in which electromagnetic body forces provide a substantial fraction of the plasma acceleration, and to a fair approximation the following simple relation may be used to estimate the thruster specific impulse (Jahn 1968):

$$
I_{s p} \approx\left[\frac{\mu_{0}}{4 \pi G} \ln \left(\frac{R_{a}}{R_{c}}\right)\right] \frac{J^{2}}{\dot{m}} \quad s
$$

where $G$ is the acceleration due to gravity $\left(9.8 \mathrm{~m} / \mathrm{s}^{2}\right)$ and $\mu_{0}$ is the permeability of free space $\left(4 \pi \times 10^{-7}\right)$. Although the specific impulse will be somewhat higher when thermal acceleration processes are included, the trends in specific impulse obtained by Equation 2 can be used to determine the cylindrical thruster geometries which produce the maximum achievable $I_{s p}$ values for a given discharge current. Once the geometries are identified, a more detailed simulation may be performed using the MHD codes discussed earlier. A simple numerical scheme was thus written to evaluate the maximum $J^{2} / \dot{m}$ and associated specific impulse values over a range of discharge currents and cylindrical thruster geometries consistent with cathode current density limitations and the geometric constraints associated with Equation 1. The results of this analysis are presented in the section below.

\section{RESULTS}

To remain within the constraints imposed by Equation 1, the assumed cathode radii considered in this study were limited to values between $5 \mathrm{~mm}$ and $25 \mathrm{~mm}$. The cathode radius in combination with the assumed cathode emission current density and given discharge current provide a minimum required cathode length for each case. Preble (1990) showed that equal electrode lengths offered the greatest self-field thruster stability, hence the anode length was set equal to the cathode length in this analysis. Consistent with the constraints on Equation 1, the anode radius was limited to values between 5 and 10 times the cathode radius, and the electrode lengths were limited to values less than 5 times the anode radius.

A simple numerical scheme was developed to evaluate the critical $J^{2} / \dot{m}$ and specific impulse values for various emission current densities and total discharge currents, subject to the above geometric constraints. For each emission current density, the minimum cathode surface area required to support a given thruster discharge current was determined. Given a cathode radius, the cathode surface area determined the necessary cathode length and, by default, the anode length of the thruster. The anode radius was then varied from 5 times the cathode radius to 10 times the cathode radius, with the constraint that the ratio of anode length to anode radius was less than 5 ; if this constraint was not satisfied, the geometry was not evaluated. The cathode radius was varied between $5 \mathrm{~mm}$ and $25 \mathrm{~mm}$, the cathode emission current density was varied between 10 and $40 \mathrm{~A} / \mathrm{cm}^{2}$, and the total discharge current was varied from $250 \mathrm{~A}$ to $10,000 \mathrm{~A}$. The variations in cathode and anode radii and corresponding variations in electrode lengths provided a matrix of long-life thruster geometries for each combination of cathode emission current density and discharge current. The maximum stable $J^{2} / \dot{m}$ and specific impulse values were calculated using Equations 1 and 2 for each combination 
of emission current density, discharge current, and thruster geometry. The geometry which provided the maximum value of specific impulse for a given emission current density and total discharge current was identified, and the results are listed in Tables 1 through 3 below. It should be noted that the maximum achievable value of specific impulse did not necessarily coincide with the maximum stable value of $J^{2} / \dot{m}$, due to the geometric coefficient in Equation 2.

Table 1 displays the optimum thruster geometry, critical $J^{2} / \dot{m}$ value, and maximum achievable $I_{a p}$ for a range of discharge currents assuming a cathode emission current density of $10 \mathrm{~A} / \mathrm{cm}^{2}$, and Table 2 lists similar parameters for a cathode emission current density of $20 \mathrm{~A} / \mathrm{cm}^{2}$. It may be possible to increase the emission current density by grooving or texturing the cathode surface, thus providing a higher surface area for thermionic emission (Gilland et al. 1990 and Myers et al. 1991). The effect of increasing the cathode emission current density to $40 \mathrm{~A} / \mathrm{cm}^{2}$ is shown in Table 3. It should be remarked that although hollow cathodes have shown the potential for sustained MPD thruster operation (Mantenieks and Myers 1992), they are not currently incorporated into MPD thruster simulations due to the added complexity of modeling the hollow cathode discharge physics (Salhi and Turchi 1992), and are not considered in this study.

TABLE 1. Optimum Geometries, Critical $J^{2} / \dot{m}$, and Maximum $I_{s p}$ Values for Various Thruster Discharge Currents. Cathode Emission Current Density $=10 \mathrm{~A} / \mathrm{cm}^{2}$.

\begin{tabular}{|c|c|c|c|c|c|c|}
\hline $\begin{array}{c}J \\
\text { (A) }\end{array}$ & $\begin{array}{c}\boldsymbol{R}_{c} \\
(\mathrm{~mm})\end{array}$ & $\begin{array}{c}R_{a} \\
(\mathrm{~mm})\end{array}$ & $\begin{array}{c}L_{c}, L_{a} \\
(\mathrm{~mm})\end{array}$ & $\begin{array}{l}\left(J^{2} / \dot{m}\right)_{c r}^{a} \\
\left(A^{2}-s / k g\right)\end{array}$ & $\begin{array}{c}\left(I_{a p}\right)_{c r}^{b} \\
(s)\end{array}$ & $\begin{array}{c}\dot{m}(A r)^{c} \\
(\mathrm{~kg} / \mathrm{s})\end{array}$ \\
\hline 250 & 5 & 35 & 80 & $6.41 \times 10^{10}$ & 1272 & $1.0 \times 10^{-6}$ \\
\hline 500 & 10 & 50 & 80 & $7.13 \times 10^{10}$ & 1171 & $3.5 \times 10^{-6}$ \\
\hline 750 & 15 & 75 & 80 & $6.64 \times 10^{10}$ & 1091 & $8.5 \times 10^{-6}$ \\
\hline 1000 & 15 & 75 & 106 & $6.49 \times 10^{10}$ & 1066 & $1.54 \times 10^{-5}$ \\
\hline 1500 & 15 & 75 & 160 & $6.20 \times 10^{10}$ & 1018 & $3.63 \times 10^{-5}$ \\
\hline 2000 & 20 & 100 & 160 & $6.07 \times 10^{10}$ & 996 & $6.59 \times 10^{-5}$ \\
\hline 2500 & 20 & 100 & 200 & $5.94 \times 10^{10}$ & 976 & $1.05 \times 10^{-4}$ \\
\hline 5000 & 25 & 125 & 318 & $5.61 \times 10^{10}$ & 922 & $4.46 \times 10^{-4}$ \\
\hline 7500 & 25 & 125 & 477 & $5.30 \times 10^{10}$ & 870 & $1.06 \times 10^{-3}$ \\
\hline 10000 & 25 & 150 & 637 & $4.19 \times 10^{10}$ & 766 & $2.39 \times 10^{-3}$ \\
\hline
\end{tabular}

${ }^{a}$ Critical $J^{2} / \dot{m}$ corresponding to maximum $I_{\Delta p}$.

${ }^{b}$ Maximum value of $I_{a p}$ based on Equation (2).

${ }^{c}$ Argon propellant, fully ionized.

Based on the critical $J^{2} / \dot{m}$ value and the discharge current, a minimum propellant mass flow rate for stable operation can be determined, and has been included in the tables. Because the stability relation (Equation 1) was derived under the approximation of fully ionized argon mass flow, there is some concern that the relation breaks down at the lower discharge currents listed in the tables. However, the low mass flow rates associated with these operating conditions ensures that the propellant is sufficiently ionized even at these low discharge currents for the full-ionization approximation to remain valid (Randolph et al. 1992). 
TABLE 2. Optimum Geometries, Critical $J^{2} / \dot{m}$, and Maximum $I_{a p}$ Values for Various Thruster Discharge Currents. Cathode Emission Current Density $=20 \mathrm{~A} / \mathrm{cm}^{2}$.

$\begin{array}{ccccccc}J & R_{c} & R_{a} & L_{c}, L_{a} & \left(J^{2} / \dot{m}\right)_{c r}^{a} & \left(I_{a p}\right)_{c r}^{b} & \dot{m}(\mathrm{Ar})^{c} \\ (\mathrm{~A}) & (\mathrm{mm}) & (\mathrm{mm}) & (\mathrm{mm}) & \left(\mathrm{A}^{2}-\mathrm{s} / \mathrm{kg}\right) & (\mathrm{s}) & (\mathrm{kg} / \mathrm{s})\end{array}$

\begin{tabular}{ccccccc}
\hline 250 & 5 & 30 & 40 & $8.59 \times 10^{10}$ & 1571 & $7.30 \times 10^{-7}$ \\
500 & 5 & 35 & 80 & $6.41 \times 10^{10}$ & 1272 & $3.90 \times 10^{-6}$ \\
750 & 10 & 50 & 60 & $7.38 \times 10^{10}$ & 1212 & $7.62 \times 10^{-6}$ \\
1000 & 10 & 50 & 80 & $7.13 \times 10^{10}$ & 1171 & $1.40 \times 10^{-5}$ \\
1500 & 15 & 75 & 80 & $6.64 \times 10^{10}$ & 1091 & $3.39 \times 10^{-5}$ \\
2000 & 15 & 75 & 106 & $6.49 \times 10^{10}$ & 1066 & $6.16 \times 10^{-5}$ \\
2500 & 15 & 75 & 133 & $6.35 \times 10^{10}$ & 1042 & $9.84 \times 10^{-5}$ \\
5000 & 20 & 105 & 199 & $5.94 \times 10^{10}$ & 976 & $4.21 \times 10^{-4}$ \\
7500 & 25 & 125 & 239 & $5.77 \times 10^{10}$ & 948 & $9.75 \times 10^{-4}$ \\
10,000 & 25 & 125 & 318 & $5.61 \times 10^{10}$ & 922 & $1.78 \times 10^{-4}$
\end{tabular}

${ }^{a}$ Critical $J^{2} / \dot{m}$ corresponding to maximum $I_{s p}$.

${ }^{b}$ Maximum value of $I_{s p}$ based on Equation (2).

${ }^{c}$ Argon propellant, fully ionized.

TABLE 3. Optimum Geometries, Critical $J^{2} / \dot{m}$, and Maximum $I_{a p}$ Values for Various Thruster Discharge Currents. Cathode Emission Current Density $=40 \mathrm{~A} / \mathrm{cm}^{2}$.

\begin{tabular}{ccccccc}
\hline & & & & & \\
$(\mathrm{A})$ & $(\mathrm{mm})$ & $\begin{array}{c}R_{a} \\
(\mathrm{~mm})\end{array}$ & $\begin{array}{c}L_{c}, L_{a} \\
(\mathrm{~mm})\end{array}$ & $\begin{array}{c}\left(J^{2} / \dot{m}\right)_{c r}^{a} \\
\left(\mathrm{~A}^{2}-\mathrm{s} / \mathrm{kg}\right)\end{array}$ & $\begin{array}{c}\left(I_{s p}\right)_{c r}^{b} \\
(\mathrm{~s})\end{array}$ & $\begin{array}{c}\dot{m}(\mathrm{Ar})^{c} \\
(\mathrm{~kg} / \mathrm{s})\end{array}$ \\
\hline & & & & & & \\
250 & 5 & 30 & 20 & $9.42 \times 10^{10}$ & 1722 & $6.60 \times 10^{-7}$ \\
500 & 5 & 30 & 40 & $8.59 \times 10^{10}$ & 1571 & $2.91 \times 10^{-6}$ \\
750 & 5 & 30 & 60 & $7.76 \times 10^{10}$ & 1420 & $7.25 \times 10^{-6}$ \\
1000 & 5 & 35 & 86 & $6.41 \times 10^{10}$ & 1272 & $1.56 \times 10^{-5}$ \\
1500 & 10 & 50 & 60 & $7.38 \times 10^{10}$ & 1212 & $3.05 \times 10^{-5}$ \\
2000 & 10 & 50 & 80 & $7.13 \times 10^{10}$ & 1171 & $5.61 \times 10^{-5}$ \\
2500 & 10 & 50 & 100 & $6.88 \times 10^{10}$ & 1130 & $9.08 \times 10^{-5}$ \\
5000 & 15 & 75 & 133 & $6.35 \times 10^{10}$ & 1042 & $3.94 \times 10^{-4}$ \\
7500 & 20 & 100 & 150 & $6.10 \times 10^{10}$ & 1001 & $9.22 \times 10^{-4}$ \\
10,000 & 20 & 100 & 200 & $5.94 \times 10^{10}$ & 976 & $1.68 \times 10^{-4}$
\end{tabular}

${ }^{a}$ Critical $J^{2} / \dot{m}$ corresponding to maximum $I_{s p}$.

${ }^{b}$ Maximum value of $I_{\Delta p}$ based on Equation (2).

"Argon propellant, fully ionized. 
Although the specific impulse values do not include a thermal acceleration component, the $\mathrm{I}_{a n}$ values listed in Table 1 indicate that, for cathode current densities of $10 \mathrm{~A} / \mathrm{cm}^{2}$, the cylindrical self-field MPD thruster with argon propellant is probably not capable of delivering specific impulse values greatly in excess of $1300 \mathrm{~s}$. Of particular interest, the calculated maximum specific impulse decreases with increasing discharge current, due to the effects of the increasing electrode dimensions on the critical $J^{2} / \dot{m}$ value required for thruster stability, and the logarithmic effect of the electrode radii in the expression for specific impulse. This trend is repeated in Table 2, which indicates that a maximum specific impulse of roughly $1600 \mathrm{~s}$ may be achieved with $20 \mathrm{~A} / \mathrm{cm}^{2}$ cathode current densities, and in Table 3, which yields the highest estimated $\mathrm{I}_{\mathrm{s}}$ of around 1720 s for a cathode current rensity of $40 \mathrm{~A} / \mathrm{cm}^{2}$.

The decrease in achievable specific impulse associated with the increase in electrode dimensions is consistent with the results of previous numerical simulations (LaPointe 1992), which predicted that higher specific impulse values could be achieved by thrusters with smaller ratios of $R_{a} / R_{C}$ and shorter electrode lengths. The geometries listed in Tables $1-3$ are the optimum cylindrical self-field thruster geometries which provide the highest specific impulse at the given discharge current, consistent with the constraints on cathode emission current density. To obtain the lower emission current densities associated with long thruster life requires larger cathodes to sustain higher discharge currents, but the larger electrode geometries reduce the stable operating regime (Equation 1) and consequently reduce the achievable specific impulse. Although not addressed in this study, uniform thermionic emission from the cathode surface is unlikely to occur in actual thruster operation. Non-uniform emission may require the use of even larger cathode surface areas to sustain the discharge current and to satisfy the requirements of long-life cathode operation, leading to a further reduction in the achievable specific impulse.

Figure 2 displays the calculated maximum achievable specific impulse as a function of discharge current for the three uniform cathode emission current densities considered in this study. Each of the calculated specific impulse values plotted in the figure corresponds to the model geometry which provided the maximum $I_{s p}$ at each current level, as listed in Tables 1 through 3 . The achievable specific impulse falls fairly rapidly with increasing discharge current, then levels off at discharge currents above $5000 \mathrm{~A}$ to approximately 900 , 1000 , and $1100 \mathrm{~s}$ for cathode emission current densities of 10,20 and $40 \mathrm{~A} / \mathrm{cm}^{2}$, respectively.

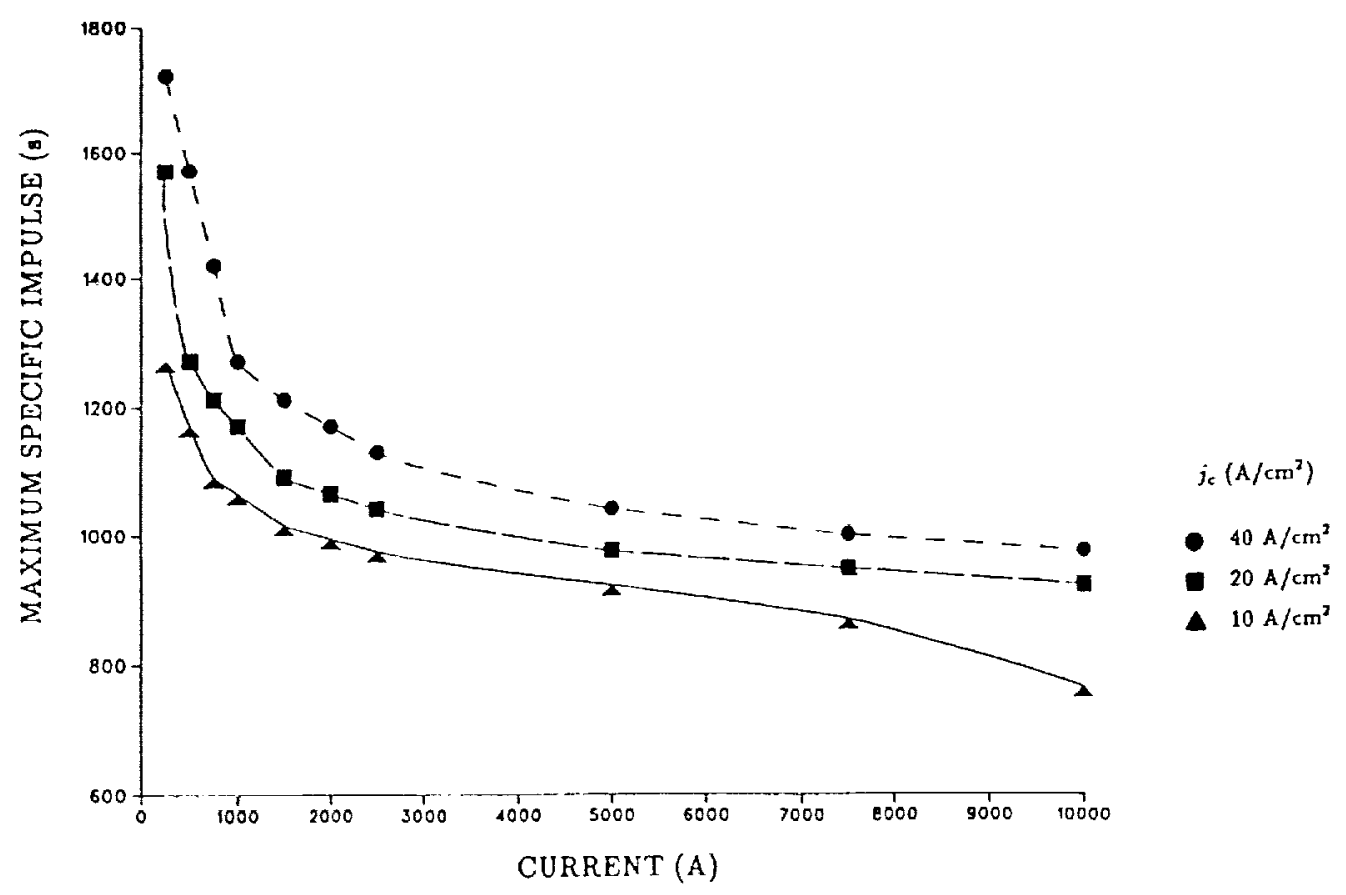

FIGURE 2. Maximum Achievable Specific Impulse, Calculated Using Equation (2). 
As noted, the values of achievable specific impulse calculated using Equation 2 do not include contributions due to thermal acceleration, hence a two-temperature MPD model was employed to better estimate thruster performance. The numerical simulations were limited to cases with cathode current densities of 20 $\mathrm{A} / \mathrm{cm}^{2}$ and $40 \mathrm{~A} / \mathrm{cm}^{2}$, due to their higher calculated specific impulse values. Electrode geometries, discharge currents, and propellant mass flow rates were obtained from Tables 2 and 3 . Electrode temperatures in the model were set uniformly to $500 \mathrm{~K}$ at the anode surface and $1500 \mathrm{~K}$ at the cathode surface. Additional information on the MHD equations and the solution technique are discussed by LaPointe (1991 and 1992). Results of the MPD thruster simulations for discharge currents of $250,500,1000,2500$, and $5000 \mathrm{~A}$ are shown in Figures 3 through 6. Figurc 3 displays the predicted specific impulse as a function of discharge current for the two cathode current densities. As expected, the trend toward decreasing specific impulse with increasing discharge current is reproduced. The values of specific impulse predicted by the MPD model are typically $20-30 \%$ higher than the values calculated using Equation 2, indicating a fairly modest thermal component to the plasma acceleration. The highest specific impulse achieved for a uniform cathode emission current of 20 $\mathrm{A} / \mathrm{cm}^{2}$ was approximately $1930 \mathrm{~s}$ at a discharge current of $250 \mathrm{~A}$. The maximum achievable specific impulse for this case rapidly decreases with increasing discharge current, and levels off at approximately $1350 \mathrm{~s}$ for discharge currents between 1000 and $2500 \mathrm{~A}$. As the discharge current is increased to $5000 \mathrm{~A}$, the maximum achievable $I_{a p}$ drops to approximately $1220 \mathrm{~s}$. Increasing the cathode emission current density to $40 \mathrm{~A} / \mathrm{cm}^{2}$ raises the maximum achievable $I_{s p}$ to $2080 \mathrm{~s}$, which again occurs for a discharge current of $250 \mathrm{~A}$. Increasing the discharge current decreases the maximum achievable $I_{s p}$ for stable thruster operation to approximately $1300 \mathrm{~s}$ at $2500 \mathrm{~A}$, after which the achievable $I_{\imath p}$ remains around $1250 \mathrm{~s}$ for higher discharge currents. It should be kept in mind that each of the maximum achievable $\mathrm{I}_{s p}$ values at each current level are generally associated with different thruster geometries, as noted in the tables.

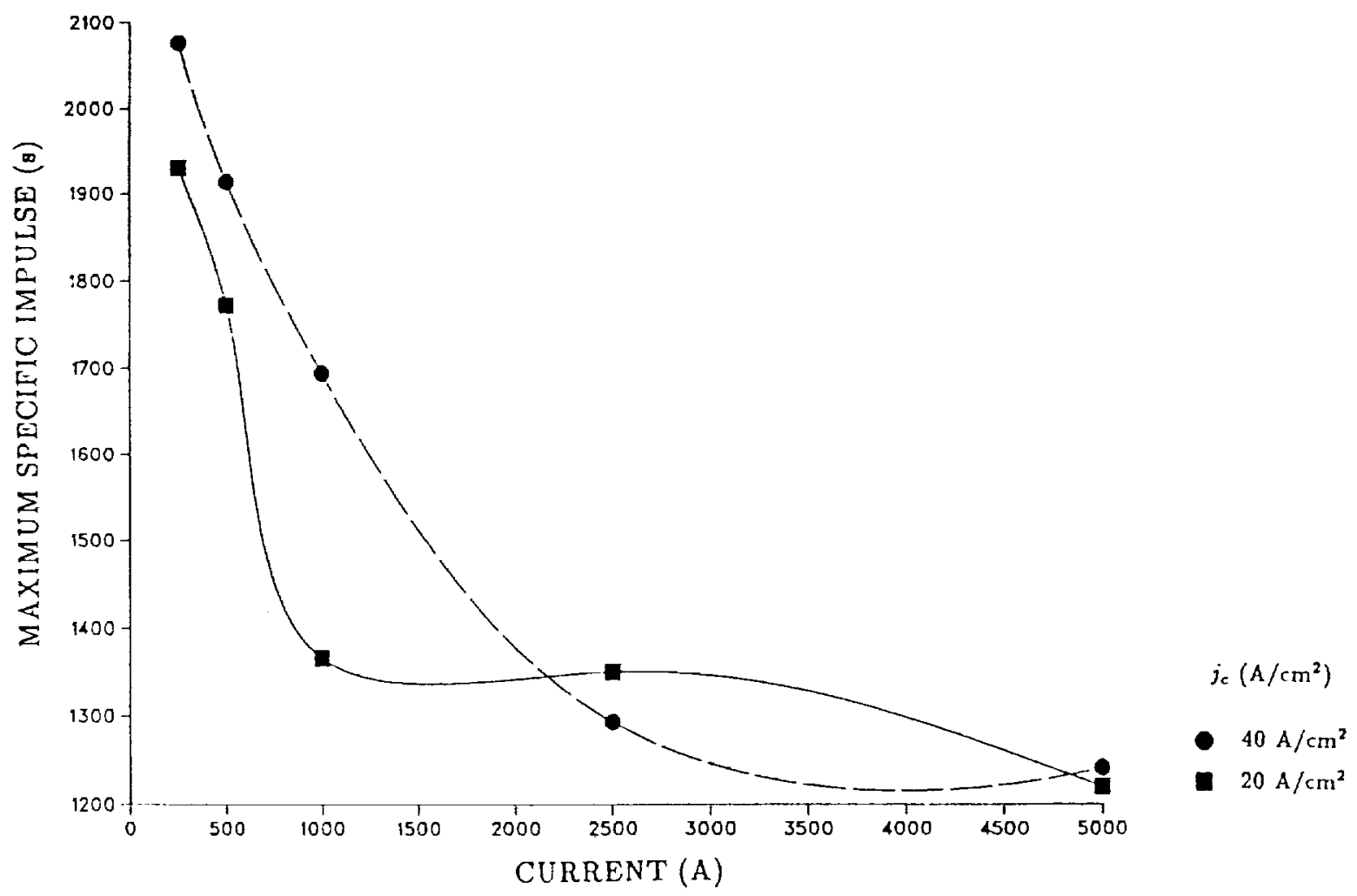

FIGURE 3. Maximum Achievable Specific Impulse, Predicted by MPDT Simulation. 
Figure 4 shows the thrust as a function of discharge current and cathode emission current density, as predicted by the two-temperature MPD thruster simulation. The thrust is similar for the $20 \mathrm{~A} / \mathrm{cm}^{2}$ and 40 $\mathrm{A} / \mathrm{cm}^{2}$ cathode emission current densities over the range of thruster discharge currents considered. This is not surprising, because at the high $J^{2} / \dot{m}$ parameters associated with the maximum $I_{o p}$ values, the thrust is primarily due to electromagnetic body forces (Jahn 1968):

$$
T(N)=\left[\frac{\mu_{o}}{4 \pi} \ln \left(\frac{R_{a}}{R_{c}}\right)\right] J^{2}
$$

The thrust is thus proportional to the square of the discharge current, multiplied by a geometric factor. Tables 2 and 3 show that the ratios of $R_{a} / R_{c}$ at each discharge current are similar, hence the thrust at each discharge current will also be similar. Additional variations in the total thrust at each discharge current are produced by the addition of thermal acceleration processes to the electromagnetic thrust, although these contributions are modest for the cases considered ( $\leq 25 \%$ of the total thrust). Viscous forces, although included in the simulations, were negligible for the cases considered.

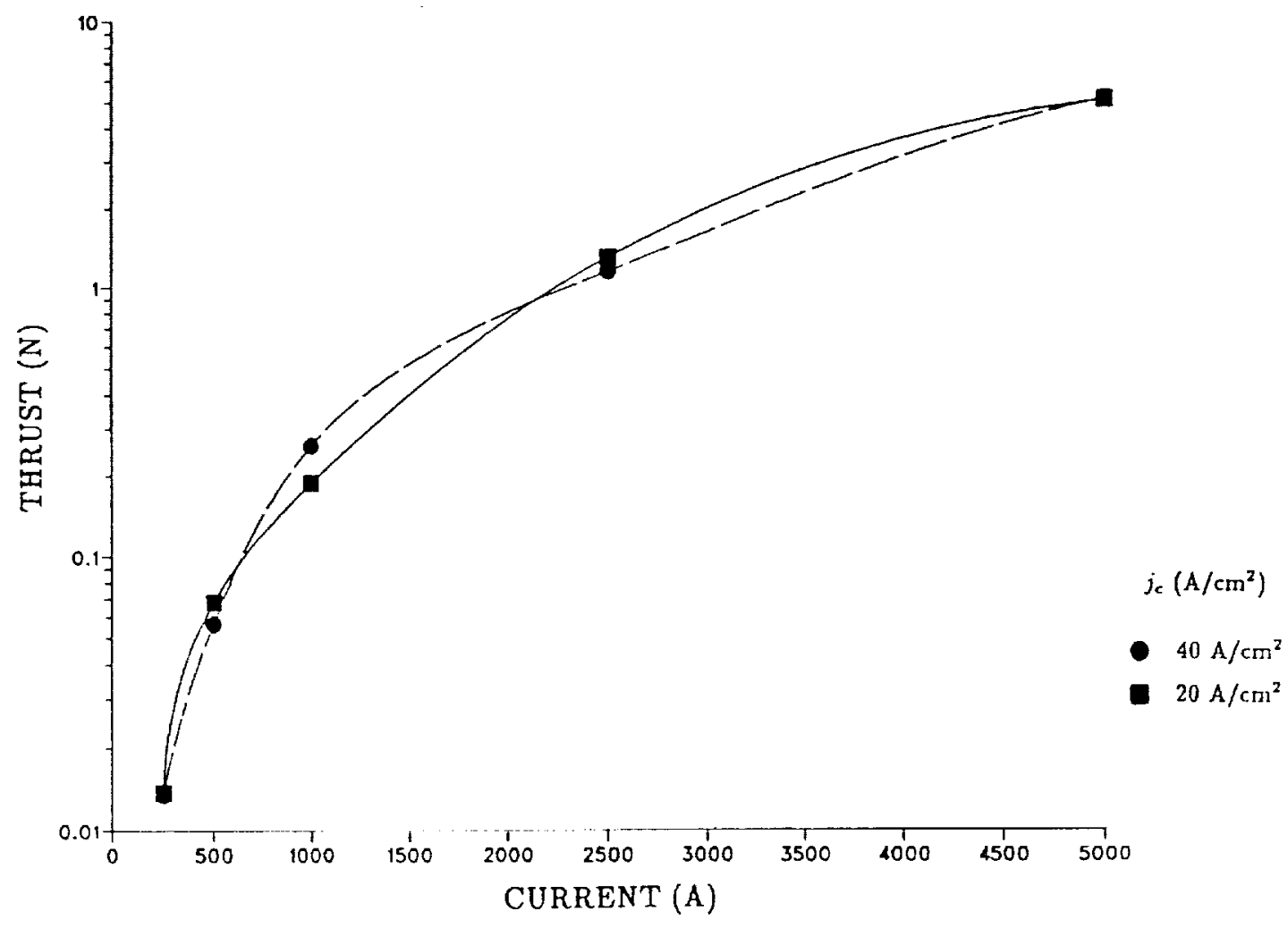

FIGURE 4. Predicted Thrust Associated with Maximum Specific Impulse Values.

Figure 5 shows the calculated plasma fall voltage as a function of discharge current, obtained by integrating the calculated electric field between the electrodes. The MPD simulation does not include electrode effects, hence an estimate of the total discharge voltage cannot be obtained. The voltage trends corresponding to the two cathode emission current densities are similar, showing a nearly linear increase in plasma potential with increasing discharge current. The plasma potential can be used to estimate the power deposited into the plasma, which can then be compared with the thrust power to determine the thruster flow efficiency $\eta_{f}$ :

$$
\eta_{f}=\frac{T^{2}}{2 \dot{m} P_{p}}=\frac{T^{2}}{2 \dot{m} V_{p} J}
$$


where $T$ denotes thrust, $P_{p}$ is the power deposited into the plasma, $V_{n}$ is the plasma fall voltage, and $J$ is the discharge current. The total thruster efficiency will be significantly less than the calculated thruster flow efficiency, primarily because of power lost to the thruster electrodes (Myers et al. 1991). Nevertheless, the trends in flow efficiency serve to identify regimes of potentially more efficient thruster operation. The flow efficiency as a function of discharge current is plotted in Figure 6 for the cases under investigation. The lowest flow efficiencies occur at the lower discharge currents, which is unfortunate since operation at the lower discharge currents produce the highest calculated values of specific impulse. The lower flow efficiencies result from the shorter electrode lengths associated with the lower discharge currents, and are consistent with previous numerical results (LaPointe 1992). The flow efficiencies generally increase with incieasing discharge current, due to an increase in the electrode lengths required to sustain the higher current levels. Thus, while the thruster geometries associated with the lower thruster discharge currents produce the highest achievable values of specific impulse, they are saddled with flow efficiencies which may render them too low to be competitive.

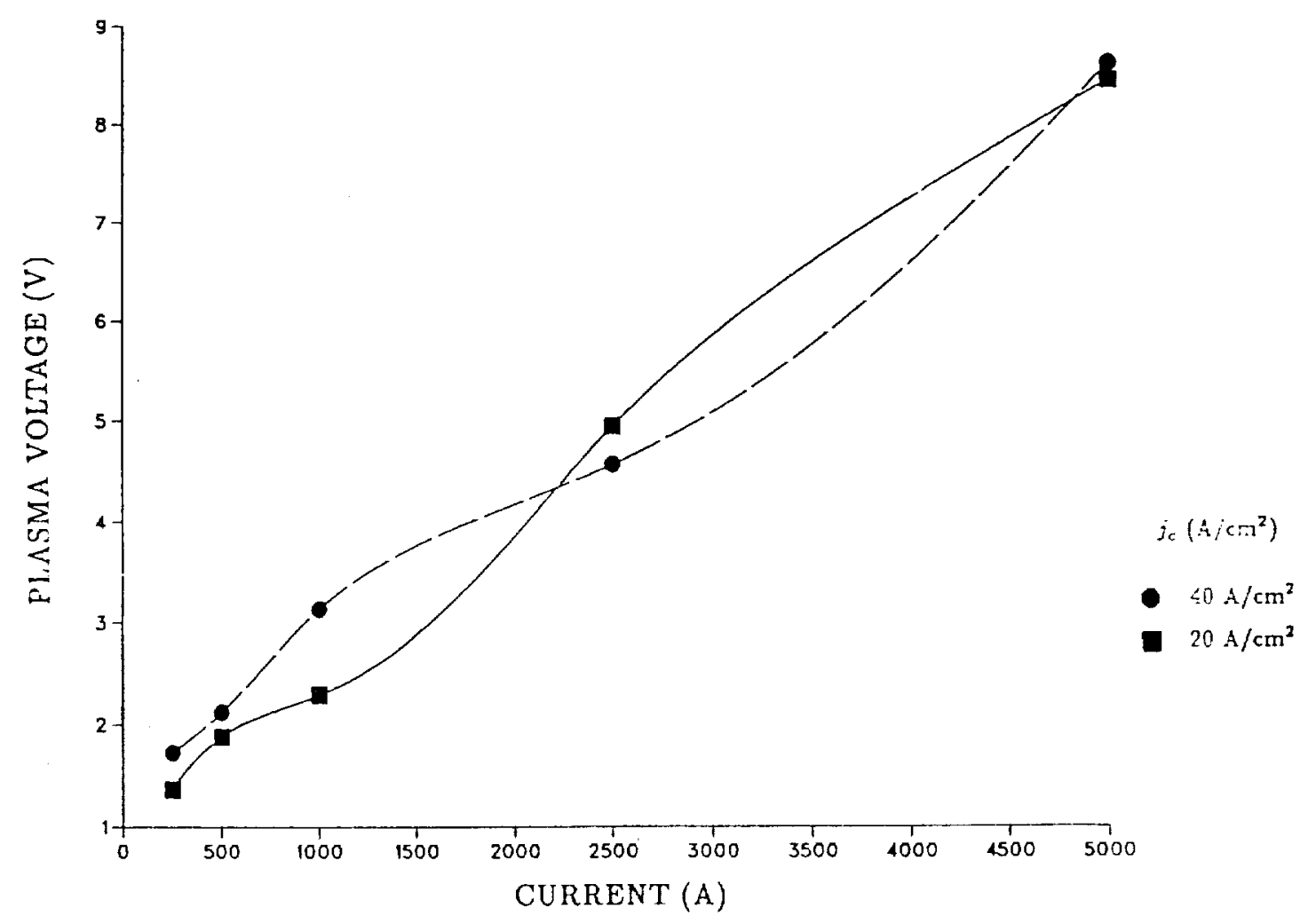

FIGURE 5. Predicted Plasma Voltage Associated with Maximum Specific Impulse Values. 


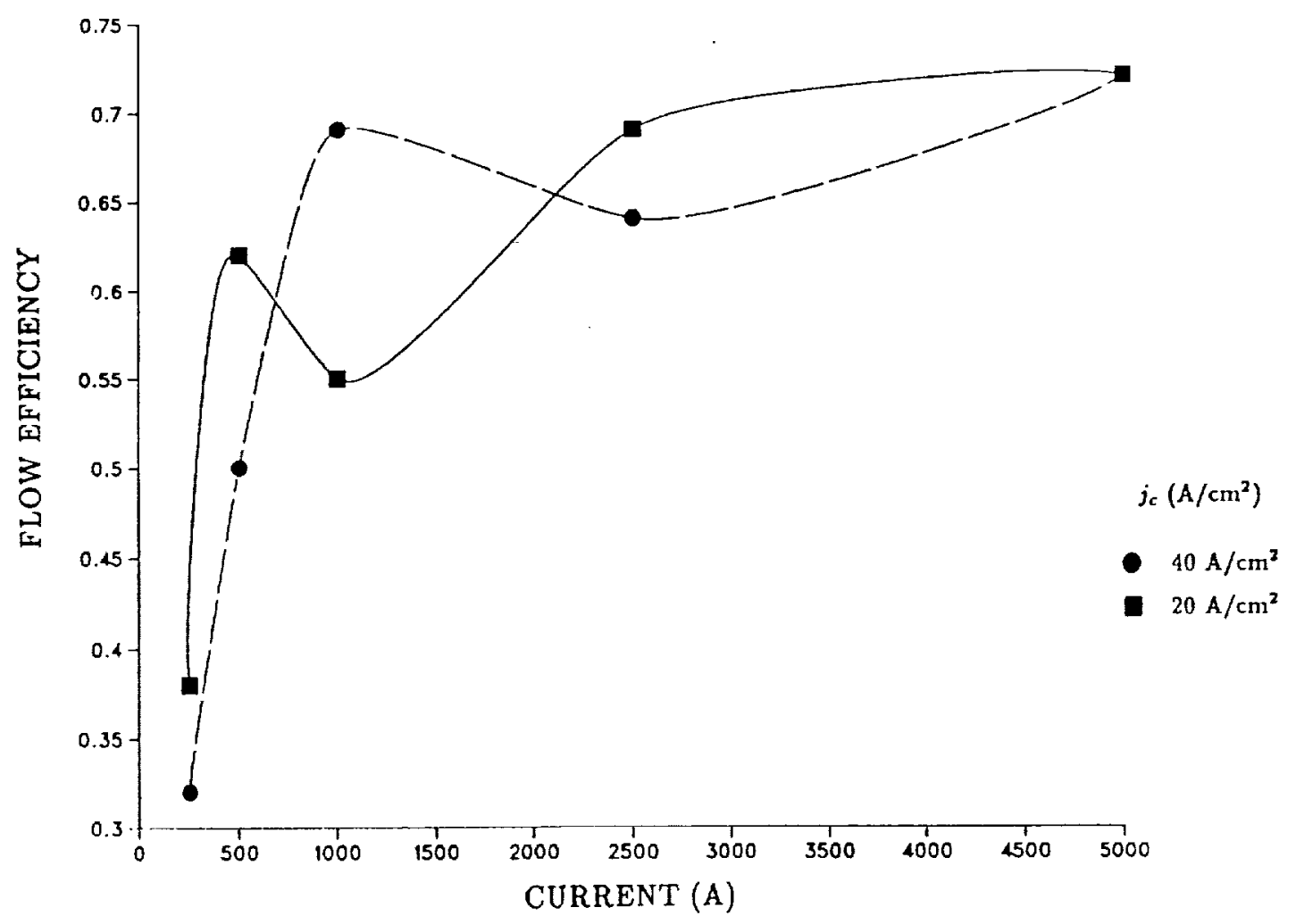

FIGURE 6. Predicted Flow Efficiency Associated with Maximum Specific Impulse Values.

\section{CONCLUSIONS}

A stability equation relating thruster discharge current, propellant mass flow rate, and electrode geometry has been solved for a variety of cylindrical self-field MPD thruster configurations. A range of uniform cathode emission current densities have been used to provide additional constraints on the thruster geometries. From the stability relation, maximum values of thruster specific impulse and the associated electrode geometries have been determined for several thruster discharge currents. A two-dimensional MPD code was then used to provide better estimates of the specific impulse, thrust, and flow efficiency for cases of interest. Results indicate that cylindrical self-field MPD thrusters operated with argon propellant may not be able to provide specific impulse values in excess of $2100 \mathrm{~s}$. The high specific impulse values are associated with lower values of the thruster flow efficiency, caused by short electrode lengths. Lengthening the electrodes improves the flow efficiency but reduces the maximum achievable specific impulse. Based on these results, it appcars unlikely that cylindrical, self-field MPD thrusters operated with argon propellant will provide the necessary combination of specific impulse, efficiency, and lifetime required for missions of interest. Attention should be focused on the use of low molecular weight propellants, alternate electrode geometries, and/or applied magnetic fields to make the MPD thruster a more viable propulsion source for high specific impulse missions. 


\section{Acknowledegments}

This work was funded by the National Aeronautics and Space Administration, Lewis Research Center, under contract NAS3-25266.

\section{References}

Choueiri, E. Y. (1991) Electron-Ion Streaming Instabilities of an Electromagnetically Accelerated Plasma, Ph.D. Dissertation, Department of Mechanical and Aerospace Engineering, Princeton University, Princeton, NJ, October 1991.

Gilland, J. H., R. M. Myers, and M. J. Patterson (1990) "Multimegawatt Electric Propulsion System Design Considerations", AIAA 90-2552, July 1990.

Hugel , H. (1980) "Effect of Self-Magnetic Forces on the Anode Mechanism of a High Current Discharge", IEEE Trans. Plasma Sci., PS-8(4): 437-442.

Jahn, R. G. (1968) Physics of Electric Propulsion, McGraw-Hill, Inc., New York, pp. 197-253.

LaPointe, M. R. (1991) "Numerical Simulation of Self-Field MPD Thrusters", AIAA 91-2341, June 1991; also see NASA CR-187168, August 1991.

LaPointe, M. R. (1992) "Numerical Simulation of Geometric Scale Effects in Cylindrical Self-Field MPD Thrusters", AIAA 92-3297, July 1992; also see NASA CR-189224, August 1992.

Lawless, J. L. and V. V. Subramaniam (1987) "Theory of Onset in Magnetoplasmadynamic Thrusters", J. Prop. and Power, 3(2): 121-127.

Mantenieks, M. A. and R. M. Myers (1991) "Preliminary Test Results of a Hollow Cathode MPD Thruster", IEPC 91-076, presented at the 22nd International Electric Propulsion Conference, Viareggio, Italy, October $14-17,1991$.

Myers, R. M., M. A. Mantenieks, and M. R. LaPointe (1991) "MPD Thruster Technology", A1AA 91-3568, September 1991; also see NASA TM-105242, September 1991.

Myers, R. M., J. E. Parkes, and M. A. Mantenieks (1992) "Multimegawatt MPD Thruster Design Considerations", in Proc. Ninth Symposium on Space Nuclear Power Systems, M. S. El-Genk and M. D. Hoover, eds., AIP Conference Proceedings 246, held in Albuquerque, NM, 12-16 January 1992.

Niewood, E. H., J. C. Preble, D. E. Hastings, and M. Martinez-Sanchez (1990) "Electrothermal and Modified Two Stream Instabilities in MPD Thrusters", AIAA 90-2607, July 1990.

Preble, J. C. (1990) Onset in Magnetoplasmadynamic Thrusters: A Model of an Electrothermal Instability, M.S. Thesis, Department of Aeronautics and Astronautics, Massachussetts Institute of Technology, Cambridge, MA, May 1990.

Randolph, T. M., W. F. von Jaskowsky, A. J. Kelly, and R. G. Jahn (1992) "Measurement of Ionization Levels in the Interelectrode Region of an MPD Thruster", AIAA 92-3460, July 1992.

Salhi, A. and P. J. Turchi (1992) "A First-Principles Model for Orificed Hollow Cathode Operation", AIAA 92-3742, July 1992.

Schroff, A. M., P. Palluel, and J. C. Tonnerre (1981) "Performance and Life Tests of Various Types of Impregnated Cathodes", Applications of Surface Science, 8 (1981):36-49. 
Sovey, J. S. and M. A. Mantenieks (1988) "Performance and Lifetime Assessment of MPD Arc Thruster

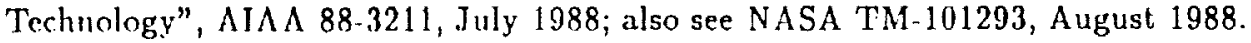

Stone, J. R. (1992) "Nuclear Electric Propulsion: An Integral Part of NASA's Nuclear Propulsion Project", in Proc. Ninth Symposium on Space Nuclear Power Systems, M. S. El-Genk and M. D. Hoover, eds., AIP Conference Proceedings 246, held in Albuquerque, NM, 12-16 January 1992.

Subramaniam, V. V. and J. L. Lawless (1988) "Electrode-Adjacent Boundary Layer Flow in Magnetoplasmadynamic Thrusters", Phys. Fluids, 31(1): 201-209.

Tahara, H., H. Yaasui, Y. Kagaya, and T. Yoshikawa (1987) "Experimental and Theoretical Researches on Are Structure in a Self-Field Thruster", AlAA 87-1093, May 1987.

Tilley, D. L. (1991) An Investigation of Microinstabilities in a kW Level Self-Field MPD Thruster, M.S. Thesis 1917-T, Department of Mechanical and Aerospace Engineering, Princeton University, Princeton, NJ, October 1991.

Wagner, H. P., M. Auweter-Kurtz, T. Roesgen, E. W. Messerschmid, and H. J. Kaeppeler (1990) "Gradient Driven Instabilities in Stationary MPD Thruster Flows", AIA A 90-2603. 
Public reporting burden for this collection of information is estimated to average 1 hour per response, including the time for reviewing instructions, searching existing data sources, gathering and maintaining the data needed, and completing and reviewing the collection of information. Send comments regarding this burden estimate or any other aspect of this collection of information, including suggestions for reducing this burden, to Washington Headquarters Services, Directorate for information Operations and Reports, 1215 Jefferson Davis Highway, Sulte 1204, Arlington, VA 22202-4302, and to the Office of Management and Budget, Paperwork Reduction Project (0704-01B8), Washington, DC 20503
1. AGENCY USE ONLY (Leave blank)
2. REPORT DATE
January 1993
3. AEPORT TYPE AND DATES COVERED
Final Contractor Report

4. TITLE AND SUBTITLE

5. FUNDING NUMBERS

Numerical Study of Cathode Emission Constraints on Cylindrical Self-Field

MPD Thruster Performance

6. AUTHOR(S)

Michael R. LaPointe

WU-506-42-31

7. PERFORMING ORGANIZATION NAME(S) AND ADDRESS(ES)

Sverdrup Technology, Inc.

Lewis Research Center Group

2001 Aerospace Parkway

Brook Park, Ohio 44142

9. SPONSORING/MONITORING AGENCY NAMES(S) AND ADDRESS(ES)

10. SPONSORING/MONITORING AGENCY REPORT NUMBER

National Aeronautics and Space Administration

Lewis Research Center

Cleveland, Ohio 44135-3191

8. PERFORMING ORGANIZATION REPORT NUMBER

E-7416

NASA CR-190795

11. SUPPLEMENTARY NOTES

Prepared for the Tenth Symposium on Space Nuclear Power and Propulsion sponsored by the Institute for Space Nuclear Power Studies, Albuquerque, New Mexico, January 10-14, 1993. Project Manager, James S. Sovey, (216) 433-7454.

12a. DISTRIBUTION/AVAILABILITY STATEMENT

12b. DISTRIBUTION CODE

Unclassified - Unlimited

Subject Categories 20 and 64

13. ABSTAACT (Maximum 200 words)

A stability equation relating thruster discharge current, argon propellant mass flow rate, and electrode geometry has been solved for a variety of cylindrical self-field MPD thruster configurations and discharge currents. Realistic values for cathode emission current densities were used to provide additional constraints on the thruster geometries. A twodimensional MPD code was employed to provide better estimates of the maximum achievable specific impulse, thrust, and flow efficiency for cases of interest. The model results indicate that long life, cylindrical self-field MPD thrusters operated with argon propellant may not be able to provide specific impulse values in excess of $2100 \mathrm{~s}$. Alternate electrode geometries, applied magnetic fields, and/or low molecular weight propellants may be necessary to achieve higher values of specific impulse.

\begin{tabular}{|c|c|c|}
\hline \multicolumn{3}{|c|}{$\begin{array}{l}\text { 14. SUBJECT TERMS } \\
\text { MPD; Electric propulsion; Numerical simulation }\end{array}$} \\
\hline $\begin{array}{l}\text { 17. SECURITY CLASSIFICATION } \\
\text { OF REPORT } \\
\text { Unclassified }\end{array}$ & $\begin{array}{l}\text { 18. SECURITY CLASSIFICATION } \\
\text { OF THIS PAGE } \\
\text { Unclassified }\end{array}$ & $\begin{array}{l}\text { 19. SECURITY CLASSIFICATION } \\
\text { OF ABSTRACT } \\
\text { Unclassified }\end{array}$ \\
\hline
\end{tabular}

